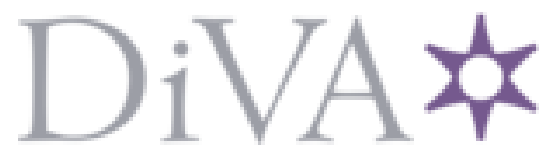

http://www.diva-portal.org

\title{
Postprint
}

This is the accepted version of a paper published in Journal of Manufacturing Technology Management. This paper has been peer-reviewed but does not include the final publisher proofcorrections or journal pagination.

Citation for the original published paper (version of record):

Löfving, M. (2016)

Homogeneity of manufacturing choices in subcontractor SMEs.

Journal of Manufacturing Technology Management, 27(2): 261-286

http://dx.doi.org/10.1108/JMTM-03-2014-0024

Access to the published version may require subscription.

N.B. When citing this work, cite the original published paper.

Permanent link to this version:

http://urn.kb.se/resolve?urn=urn:nbn:se:hj:diva-28693 


\section{Homogeneity of manufacturing choices in subcontractor SMEs}

\section{Structured Abstract:}

Purpose: This paper investigates the choices made in manufacturing decision categories by subcontractor small and medium-size enterprises (SMEs) and determines if subcontractor SMEs make homogenous manufacturing choices.

Design/methodology: A literature review was used to develop theoretical propositions. A multiple case study with 19 subcontractor SMEs was conducted.

Findings: Factors that might lead to homogenous choices in the manufacturing strategy decision categories were formalised into four theoretical propositions. The propositions were based on new institutionalism factors as well as SME factors. The findings reveal that there is considerable heterogeneity across the subcontractor SMEs in the various manufacturing decision categories. However, there are similarities between some manufacturing choices. This can partly be explained by the proposed factors and partly by other factors, such as SME characteristics and process choices.

Research limitations/implications: The study reinforces the need for more research that is focused on manufacturing decisions and choices in SMEs. All cases were of Swedish SMEs belonging to three different industries, potentially limiting the generalizability of findings to other industries or countries.

Practical implications: This study highlights the importance of the different choices made considering manufacturing and the factors influencing those choices. This provides guidance for managers when they make manufacturing choices in various decision categories.

\section{Introduction}

Operations managers make strategic manufacturing decisions that influence manufacturing capabilities and, on an overall level, competitiveness. These decisions typically include choices concerning resource allocation, capacity issues, investment, process technology, degree of vertical integration, manufacturing management and organisational issues. The pattern of these manufacturing decisions, which constitute manufacturing choices, influences a company's ability to sustain competitiveness. Manufacturing decisions are among the core elements of manufacturing strategy and should support a company's ability to successfully achieve its competitive priorities and sustain competitiveness (Skinner, 1969; Diaz Garrido et al., 2007). Therefore, it is crucial that a manufacturing company has a good understanding of its manufacturing decisions and choices. 
There has been increased recognition of the need to include contextual factors in the development of manufacturing strategy theory (see, e.g., Ketokivi and Schroeder, 2004; Sousa and Voss, 2008). According to Sousa and Voss (2008), the manufacturing strategy contingency paradigm requires internal and external consistency between manufacturing strategy choices in order to increase performance (see, e.g., Hayes and Wheelwright, 1984). According to Choudhari et al. (2012b, p. 1338), "It is essential to understand how ... factors affect decision choices in order to develop a sound manufacturing strategy."

Size is one of the original contingency variables discussed by, among others, Woodward (1958) and Child (1972). Most studies of decision categories have not considered company size. Researchers and practitioners argue that, as subcontractors, small and medium-sized enterprises (SMEs) play a major role in the economy and in global supply chains (Thakkar et al., 2012; Hilmola et al., 2015). Previously, it was generally assumed that manufacturing practices were equally applicable to SMEs and large companies (Cagliano et al., 2001). However, research has shown that SMEs exhibit different characteristics to larger companies and are not simply small versions of the latter (Storey, 1994; Cagliano et al., 2001; Bridge et al., 2009). Therefore, it is crucial to adapt manufacturing strategy decision categories to the context in which they will be used. However, there have been very few empirical investigations of manufacturing choices in SMEs. It is hoped that this paper will increase understanding of such choices.

Ketokivi and Schroeder (2004) argued that contextual factors must be understood by manufacturing managers in order for a company to be able to remain competitive. However, they did not find an adequate explanation of why particular companies adopt certain manufacturing practices. They therefore suggested that manufacturing managers might mimic others in their choices, resulting in a mismatch between strategies and manufacturing. This might lead to greater homogeneity among companies, which is consistent with new institutionalism theory (DiMaggio and Powell, 1983). In contrast to the homogeneity proposition made by new institutionalism theory, previous studies of SMEs have shown that they cannot be divided into homogenous groups based on their numbers of employees (Barad and Gien, 2001; Cagliano and Spina, 2002; O'Regan and Ghobadian, 2004; Assarlind and Gremyr, 2013). This raises an important question: Do subcontractor SMEs behave in similar ways and make similar manufacturing choices? The aim of this paper is to increase knowledge of the manufacturing choices made by subcontractor SMEs and to investigate whether these choices are homogeneous.

The remainder of the paper is structured as follows. First, the relevant literature is reviewed and theoretical propositions are developed. Second, the research methodology is outlined. Thereafter, the empirical and theoretical findings are described and then analysed. Finally, the paper concludes with a discussion of the implications of the findings of the study.

\section{Theoretical framework and development of propositions}

\subsection{Manufacturing strategy}

To sustain competitiveness in today's turbulent market environment, companies must understand market demands (Porter, 1985; Slack and Lewis, 2011). In order to satisfy changing market requirements, companies must achieve superior manufacturing performance. Since Skinner's (1969) seminal article about the importance of manufacturing in an organisation, most companies have agreed that manufacturing must support the overall objectives of a company. Skinner (1969) claimed that the manufacturing decisions made by a company would have an effect on strategies and, ultimately, on competitiveness. Since then, it has become clearer that manufacturing may constitute a major competitive advantage (e.g. Hayes and Wheelwright, 1984; Hill and 
Hill, 2009, Hilmola et al., 2015). To gain and maintain a competitive advantage, it is important to make the right decisions in manufacturing that support the overall objectives of the company and meet market requirements. This is achieved by means of a manufacturing strategy.

A manufacturing strategy is a functional strategy that can operate only in conjunction with other strategies, such as marketing, R\&D and accounting strategies (Säfsten et al., 2007). Functional strategies should be linked and coordinated with business strategies. If these two types of strategy are not linked together, then the decisions that are made might not correspond to one another within each function or across functions, and this incongruity could lead to misdirection and obstruct the company from reaching its objectives (Hill and Hill, 2009). In the area of manufacturing strategy, it is common to distinguish among content, i.e. the constituents of a manufacturing strategy (Voss, 1995), process, i.e. how a strategy is formulated and implemented (Voss, 1995), and context, i.e. the set of circumstances under which a business operates (Mills et al., 1995).

The manufacturing strategy process is "a pattern or procedure in which manufacturing strategy is developed and implemented" (Dangayach and Deshmukh, 2001, p. 887), but can also be viewed as a sequence of decisions in the company's decision-making behaviour (Paiva et al., 2008). The manufacturing strategy process is commonly divided into formulation and implementation (Leong et al., 1990; Mills et al., 1995, Paiva et al., 2008), even though these can be intertwined (Barnes, 2002; Jagoda and Kiridena, 2015). Manufacturing strategy formulation concerns different ways of aligning competitive priorities with decision categories, while manufacturing strategy implementation concerns the execution of the manufacturing strategies (Slack and Lewis, 2011).

The predominant model for manufacturing strategy content was summarised by Leong et al. (1990). Their model identified two major constituents of manufacturing strategy content: competitive priorities and decision categories. These two constituents of a manufacturing strategy are acknowledged in Slack and Lewis's (2011, p. 22) definition of manufacturing strategy: "the total pattern of decisions that shape the long term capabilities ... and their contribution to overall strategy through the reconciliation of market requirements with [manufacturing] strategy". The pattern of manufacturing choices and decisions directly affects an organisation's ability to compete in the market (Jagoda and Kiridena, 2015). Competitive priorities are met through different sets of decision categories (Miltenburg, 2005; Slack and Lewis, 2011). Decision categories consist of a few alternative manufacturing choices (Choudhari et al., 2010).

\subsection{Decision categories}

In manufacturing strategy theory, manufacturing choices are often grouped into a number of decision categories (Hayes and Wheelwright, 1984; Miltenburg, 2005) and are "defined by the pattern of manufacturing choices that a company makes” (Miller and Roth, 1994, p. 285). Since Hayes and Wheelwright (1984) introduced the concept of decision categories, numerous researchers have contributed to the development of these categories (e.g., Leong et al., 1990; Olhager and Rudberg, 2002; Dìaz Garrido et al., 2007; Alves Filho et al., 2015). Decision categories are divided into structural and infrastructural categories, as proposed by Hayes and Wheelwright (1984). In the present paper, structural and infrastructural decision categories are adapted from Miltenburg (2005); see Table 1. Each of the various decision categories has different considerations regarding which different manufacturing choices may be made (Miltenburg, 2005; Choudhari et al., 2010); see Table 1. Different manufacturing choices are required for different missions, and the focus and choices need to change in accordance with changes in markets, products or 
technology (Hayes et al., 2005). Manufacturing choices may also affect one other, as well as competitive priorities (Alves Filho et al., 2015).

\section{[Insert Table 1 here]}

\subsection{Empirical research on decision categories in SMEs}

There have been a few studies of decision categories and manufacturing choices in the context of SMEs. For example, Raymond (2005) focused on advanced manufacturing technology in SMEs and its relationship to contingency factors. Koc and Bozdag (2007) investigated how the use of computer numerically controlled (CNC) machines in manufacturing SMEs could enhance competitive priorities and their performance. Some studies have included both SMEs and larger companies, and their results have been independent of company size (e.g., Choudhari et al., 2012a; 2012b). Choudhari et al. (2012a, 2012b) investigated the relationship between decision categories, process choices and specific factors of non-process choices (e.g., product complexity, strategic orientation in manufacturing, top management and size). They found some evidence of a relationship between specific decision categories and specific factors such as process choices, and they concluded that other contextual factors might have a closer relationship with the decision categories than did the factors they studied.

However, there have also been investigations of specific decision categories for SMEs, and these will be discussed below.

Various studies have described human resource management in SMEs as informal and without a written recruitment process (see, e.g., Julien, 1998; Tsai, 2010). However, the level of formalisation in human resource management increases with company size (see, e.g., Nguyen and Bryant, 2004). Recruitment criteria are often subjective, such as maturity and ambition or motivation (Julien, 1998; Stewart and Knowles, 2000; Rantakyrö, 2004). A study of graduate recruitment in the UK (Stewart and Knowles, 2000) rated the skills and qualities of graduates. This study showed that SMEs rated motivation as most important when employing people with higher education.

Choudhari et al. (2012a; 2012b) showed that SMEs spend less time on training and education than larger companies. Reasons for this include the size of the organisations and their focus on problem solving. Rantkyrö (2004) and Garengo et al. (2005) noted that all staff were involved in daily activities and had no extra time for additional activities. According to Grando and Belvedere (2006), the decision-making process in SMEs is informal and centralised owing to the organisations' size. Staff participation in decision making is rare, and it is usually the owner-manager or top management who make the majority of decisions (Bridge et al., 2009; Rantakyrö, 2004). Previous studies of continuous improvements in SMEs (Alstrup, 2000) have shown that this centralised decision-making, hierarchical management style is an obstacle to employee involvement in problem solving and in making continuous improvements. The formality of decision making increases with the number of employees, as shown by O'Regan and Ghobadian (2004) and Choudhari et al. (2012a; 2012b). This is also true for planning, according to Choudhari et al. (2012a; 2012b).

There have been various studies of advanced manufacturing technology (AMT) in different contexts, including SMEs (e.g. Raymond, 2005; Koc and Bozdag, 2007). Swamidass and Kotha (1998) found that the size of a company influenced its use of AMT. In other words, AMT use is lower in small companies than in larger companies. Choudhari et al. (2012a; 2012b) also studied AMT, as part of "process technology", but they found no evidence that a company's size influenced its use of AMT. 
Previous studies have shown that various decisions are influenced by the choice of process; this is true in particular of production planning and control and of process technology (e.g. Safizadeh and Ritzman, 1997; Olhager and Rudberg, 2002; Choudhari et al. 2012a; 2012b). Choudhari et al. (2012a; 2012b) studied job shops and batch flow, and Safizadeh and Ritzman (1997) studied job shops in companies of different sizes. As found by various studies, both planning input and master production schedule (MPS) are influenced by the choice of process (see, e.g., Safizadeh and Ritzman, 1997; Olhager et al., 2001; Olhager and Rudberg, 2002; Miltenburg, 2005; Choudhari et al., 2012a; 2012b). It has been proposed that the job shop and batch flow should use customer orders as planning input and should follow a make-to-order (MTO) plan in the MPS (Safizadeh and Ritzman, 1997; Olhager et al., 2001; Miltenburg, 2005; Choudhari et al., 2012a; 2012b). It has also been suggested that the job shop and batch flow should use a push system (Olhager and Rudberg, 2002; Choudhari et al., 2012a; 2012b). Choudhari et al. (2012a) also found that small companies have a centralised planning process. It was found that job shops and batch flows carry high levels of raw materials and works-in-progress (WIP) (Safizadeh and Ritzman, 1997; Hill and Hill, 2009). Miltenburg (2005), however, argued that the inventory of raw materials should be low, since products change from customer to customer. The inventory of finished goods should be low in a job shop and in batch flow, owing to the use of MTO (Safizadeh and Ritzman, 1997; Hill and Hill, 2009). It has been suggested that general-purpose machines are appropriate for handling the large variety of products in a job shop (Miltenburg, 2005); this was found empirically by Choudhari et al. (2012a; 2012b). According to Choudhari et al. (2012a; 2012b), it is difficult to automate the handing of materials in job shop and batch flow layouts, owing to the wide variety of components and the low volumes involved. Studies of the use of quality management systems, such as total quality management (TQM) (Choudhari et al., 2012a; 2012b), have not shown any consensus, but also they have not indicated whether their case companies were ISO certified. Olhager et al. (2001) argued that a job shop is likely to lead capacity. Choudhari et al. (2012a; 2012b) indicated that the capacity strategy seemed to be related to the size of the company.

\subsection{Factors influencing decision categories}

The existence of a relationship between decision categories and performance has long been supported by the manufacturing strategy literature (Swamidass and Kotha, 1998; Ward and Duray, 2000; Raymond, 2005; Grando and Belvedere, 2006). For example, Dìaz Garrido et al. (2007) showed that performance was positively related to decision categories. A number of studies have shown a relationship between decision categories, competitive priorities and manufacturing capabilities (e.g., Narasimhan and Das, 1999; Olhager et al.2 2001; Größler and Grübner, 2006). Several studies have described decision categories in different contexts, such as product complexity (Spring and Dalrymple, 2000; Choudhari et al., 2012a; 2012b) and process choice (Safizadeh and Ritzman, 1997; Olhager and Rudberg, 2002; Hill and Hill, 2009; Choudhari et al., 2012a; 2012b). Some authors (Spring and Dalrymple, 2000; Cagliano et al., 2001; Choudhari et al., 2012a; 2012b) have observed that company size (i.e., number of employees) influences decision categories. These factors have generally been used to understand how specific decision categories can be helpful in increasing performance and to explain how decision categories are related to internal and external contexts of the organisation (e.g., Raymond, 2005; Dìaz Garrido et al., 2007).

St. John et al. (2001) and Ketokivi and Schroeder (2004) proposed that new institutionalism is a way to understand why companies make certain manufacturing choices. Institutional theory is rarely used in the study of manufacturing strategy issues 
(St. John et al., 2001; Ketokivi and Schroeder, 2004), but, according to St. John et al. (2001, p. 151), "it holds great promise in explaining why the production cores of competing firms are so often similar, why generic improvement programs are so readily adopted, and the role of suppliers, customers, and other external constituencies in driving the sameness that undermines opportunities for competitive advantages". In addition, Ketokivi and Schroeder (2004) concluded that both new institutionalism and other factors have some merit in explaining observed phenomena. Based on these insights, we pose the proposition that subcontractor SMEs' mimicry of each other is based on both new institutionalism and SME-specific factors. Theories about new institutionalism and the proposed SME-specific factors that influence manufacturing choices are further clarified below.

\subsubsection{New institutionalism}

DiMaggio and Powell (1983) argued that organisations in the same field begin to resemble one another over time and therefore will have similar practices, structures, cultures and outputs. From the manufacturing company's point of view, key institutions that work to establish norms include ISO certifications, suppliers, customers, professional organisations, and improvement programmes (St. John et al., 2001). According to DiMaggio and Powell, there are three mechanisms that lead to organisations coming to resemble each other: mimetic isomorphism, coercive isomorphism and normative isomorphism. Mimetic isomorphism results from responses to uncertainty. When organisations face uncertainties about technologies and markets, they tend to imitate other organisations (DiMaggio and Powell, 1983; St. John et al., 2001; Ketokivi and Schroeder, 2004; Tsai 2010). One example is the widespread adoption of lean production. St. John et al. (2001, p. 151) argued that "within operations, the tendency for firms within an industry to move toward standard products, similar process technologies, and similar degrees of vertical integration is evidence of mimetic isomorphism". Coercive isomorphism is caused by external pressures, such as regulatory and political pressures. Examples of coercive forces are when powerful customers may require the supplier to adopt certain practices or principles, as for example ISO 9000, ISO 14000, or 5S. These regulations and standards create similarities in the competitors, and result in standardised products and processes (DiMaggio and Powell, 1983; St. John et al., 2001; Ketokivi and Schroeder, 2004). Normative isomorphism is associated with similarities in employee groups, for example those with similar educational backgrounds, educational institutions and industry experiences. These groups tend to define problems in the same way (DiMaggio and Powell, 1983; St. John et al., 2001; Tsai 2010). This is exemplified in SME theory, since it has been proposed that graduates are under-represented in SMEs (see, e.g., Storey, 1994; Stewart and Knowles, 2000; Sear et al., 2012) and that there might be a low level of recognition of the need for a graduate. Sear et al. (2012) found that many SMEs do not see graduates as a "natural source of recruitment" and that this might lead to a more homogenous employee group.

New institutionalism proposes that organisations within the same industry imitate competitors and, over time, come to resemble one another. This theory also proposes that normative isomorphism helps explain similarities in the employee group. This leads to Propositions 1 and 2:

Proposition 1: Subcontractor SMEs within the same industry make homogenous manufacturing choices.

Proposition 2: Subcontractor SMEs have similar employee groups, leading to homogenous manufacturing choices. 


\subsubsection{SME definition}

There is no single uniform definition of what constitutes a small or medium-sized enterprise (McCartan-Quinn and Carson, 2003; Carter and Jones-Evans, 2006), and the definition differs from country to country (Yosuf and Aspinwall, 2000; Carter and JonesEvans, 2006). SMEs in Europe are defined according to the European Commission's (2014) definition (Table 2). This definition also takes account of whether SMEs are autonomous or partners. To be considered autonomous, no more than $25 \%$ of the company should be owned by another company, and the company should not own more than $25 \%$ of another company (European Commission, 2014). Since small, medium and large companies are defined in this way in Europe, it is of interest to investigate this further. Therefore, the following proposition was developed:

Proposition 3: Subcontractors with similar numbers of employees (of small or medium size according to Table 2) make homogenous manufacturing choices.

\section{[Insert Table 2 here]}

Furthermore, O’Regan and Ghodadian (2004) analysed the European Commission's definition and found that size was not the discriminating factor influencing strategies. They concluded that factors other than size might be more significant. In 2006, Ghobadian and O'Regan (2006) continued their investigation and studied patterns of ownership type. They divided SME ownership into the categories of independent (autonomous) and dependent (partner), and they claimed that there are fundamental management differences between these two organisational forms. Previous studies have shown that dependent companies, i.e. subsidiaries, are less likely to engage in risky or long-term projects (Ghobadian and Gallear, 1997). Dependent companies often have divided ownership/management, whereas the owner is often the manager in an independent company. In an independent company, the owner-manager's interests and competence, for example the manager's personality (Ghobadian and Gallear, 1997), influence the organisation. Therefore, the following proposition was developed:

Proposition 4: SMEs of the same ownership type make homogenous manufacturing choices.

In contrast to this proposition, studies of quality management and manufacturing strategy in SMEs have shown that different ownership types lead to heterogeneous choices. Yusof and Aspinwall (2000) treated dependent units and plants similarly to how they treated independent SMEs, and they were joined in this approach by Säfsten and Winroth (2011). Säfsten and Winroth (2011, p. 4) argued that "a small unit within a large international company group could very well face the same problems as an independent company". Since research on ownership type has produced contrasting results, it is of interest to investigate this further.

\subsubsection{SME characteristics}

This study recognises the need to take the context of SMEs into account when investigating decision categories, so it is relevant to present factors specific to SMEs that might be influential when making manufacturing choices. Undoubtedly, SMEs differ from large companies in their numbers of employees. However, there are other differences between SMEs and large companies besides this. These characteristics are commonly perceived as 
being a consequence of the structural and cultural environments in which these companies operate (Hudson Smith and Smith, 2007). The characteristics of SMEs generally include management practices, the organisational environment, limited resources, the operational focus and the competitive environment (markets, customers, competitors; see, e.g., Storey, 1994; Ghobadian and Gallear, 1997; Julien, 1998; Hudson et al., 2001; McCartan-Quinn and Carson, 2003; Garengo et al., 2005; Grando and Belvedere, 2006; Hudson Smith and Smith, 2007; Bridge et al., 2009).

\section{Research methodology}

\subsection{Research approach}

A multiple case study approach was the main research method used in this study. The aim of using this method was to provide insights into what manufacturing choices subcontractor SMEs make. Case studies are useful when studying a phenomenon in its real-life environment, where interactions between the phenomenon and its context are to some extent unclear (Yin, 2009). Further, case studies permit data to be collected from multiple sources of evidence, which can reveal synergistic effects and help to ensure the validity of the data (Eisenhardt, 1989; Yin, 2009). The multiple case study is also useful for discovering patterns to confirm or refute theoretical propositions (Yin, 2009).

\subsection{Sample}

The sample was drawn from manufacturing companies/units with more than 10 and fewer than 250 employees in Jönköping County in Sweden. The companies participated in three different research projects, which were carried out from March 2007 to December 2007. Each project was aimed at a single manufacturing industry: polymer manufacturers, foundries or automotive parts manufacturers. First, each project comprised 10-15 SMEs, for a total of 35 companies, which included both original manufacturers and subcontractors. It became obvious that the companies participating in the projects were not a homogeneous group, and it was difficult to draw general conclusions, since there was insufficient replication. Inspired by the work of Cagliano and Spina (2002), which separated subcontractors and original manufacturers, we considered only the 19 subcontractors, and the replication was more visible. The respondent subcontractors had no product development and did no assembly work. These 19 subcontractors had similar market conditions, and they were in a highly competitive environment that faced uncertainties from low-cost industries in other countries. Their customers were both domestic and international and were medium-sized or larger original manufacturers. The subcontractors had either job shop or batch flow types of process choices, in accordance with Hill and Hill (2009). The characteristics of the 19 companies are presented in Table 3.

\section{[Insert Table 3 here]}

\subsection{Data collection}

Data were collected by means of a series of face-to-face interviews and observations with key respondents (see Table 3). Before the interviews were carried out, a structured interview guide was designed for each research project. This guide included questions for the specific project and general questions for this research study. The interviews lasted 1 to $1 \frac{1}{2}$ hours and were recorded and transcribed. After each interview, the manufacturing managers led a guided tour of their respective companies. Notes were taken during the tour. In addition, company documentation was gathered and analysed. 
The unit of analysis in the case companies was the manufacturing system in subcontractor SMEs.

\subsection{Data analysis}

An adapted version of Radnor and Boaden's (2004) six-step approach for analysing qualitative multiple-case research data was used in this study. First, topics and categories were constructed from the propositions and literature. A database consisting of the manufacturing choices was created in Excel to manage the data analysis. Thereafter, each company was analysed according to Miltenburg's manufacturing choices, as shown in Table 1. All respondents' answers considering manufacturing choices were included in the database, although some were excluded due to missing data. Thereafter, the data were subjected to a cross-case analysis (Yin, 2009), in which various empirical patterns were compared with the theoretical propositions. This resembles the analysis technique of pattern matching described by Yin (2009). The empirical findings were also compared with the existing literature (e.g., Safizadeh and Ritzman, 1997; Choudhari et al., 2012a; 2012b). The similarities and differences between the findings and theoretical propositions were discussed and conclusions were drawn.

\section{Empirical findings}

The research findings presented here are based on the decision category suggested by Miltenburg (2005) using the summary matrix-based analysis findings of Table 4. Throughout this section, the manufacturing choices in the studied SMEs are identified and analysed and compared with what is found in the existing literature. The findings are related to the theoretical propositions.

\subsection{Human resources}

In general, a majority of the companies in the study preferred to promote people internally. Hence, promotion within the small subcontractors was a complex issue. On the one hand, it was difficult to be promoted, owing to the small size of the organisation, the narrow range of jobs available and the low employee turnover. On the other hand, a skilled and motivated employee could easily be promoted, since the CEO knew most of the employees and promoted individuals who were considered suitable for a position. In the mediumsized subcontractors, there were more positions, because of the greater size of the organisation and the wider range of jobs available.

Previous research studies have argued that recruitment criteria are often subjective factors, such as maturity, ambition and motivation (Julien, 1998; Stewart and Knowles, 2000; Rantakyrö, 2004). This is consistent with the findings of this study, since most of the companies studied preferred to recruit internally. When necessary, companies F7, F9, AP2, P2, P3, P4, P5 and P8 recruited externally. When recruiting externally, subcontractors preferred to recruit through personal acquaintances. The subcontractors also stressed that it was difficult to find and employ graduates, such as engineers, because of their location and limited financial resources. These issues were also highlighted by Sear et al. (2012).

Choudhari et al. (2012a; 2012b) found that over 70\% of their case companies had skilled employees, and they related this to the process choice. The findings of this study are different from those of Choudhari et al. In this study, independently of process choice, the smaller companies had either multiskilled or skilled employees. Eight of the 11 small companies in this study (F3, F5, F6, AP1, P2, P3, P5 and P7) had multiskilled employees. The medium-sized companies (F2, F8, F9, AP2, P4, P6 and P8) in this study had all skilled employees. This indicates that number of hierarchical levels, job classification and number 
of employees in a company influence whether the employees are multiskilled or not, contrary to the findings of Choudhari et al. (2012a; 2012b).

Alstrup (2000) found that centralised decision making and the manager's personality prohibited the involvement of subordinates in problem solving. However, there was no consensus regarding whether the employees of subcontractors participated in problem solving or decision making.

\section{[Insert Table 4 here]}

\subsection{Organisational structure and control}

One of the shared characteristics of SMEs is informal centralised decision making (see Hudson et al., 2001; Rantakyrö, 2004; Bridge et al., 2009). The formality has been shown to increase with increasing company size (e.g., O’Regan and Ghobadian, 2004; Choudhari et al., 2012a; 2012b). The findings of the present investigation verify this, since all the studied subcontractors had centralised decision making. In this study, this meant that most of the decisions were made by the CEO or the manufacturing manager. In addition, the smaller companies in this study (F1, F3, F5, F6, F7, AP1, P1, P2, P3 and P5) had a more informal decision-making process than the medium-sized case companies (F2, F8, F9, AP2, P4, P6 and P8). For example, the CEOs in company F1 were involved in most of the decisions, including operational decisions concerning manufacturing, while in the medium-sized subcontractors, the CEO delegated operational decisions to the manufacturing manager and the quality manager.

Choudhari et al. (2012a; 2012b) identified the number of hierarchical levels in companies and found that small companies had fewer levels. This corresponds to the findings of the present study. In all of the small subcontractors (F1, F3, F5, F6, F7, AP1, P1, P2, P3 and P5), the hierarchy consisted of two levels, namely a CEO and a manufacturing manager/foreman, while the medium-sized subcontractors (F2, F8, F9, AP2, P4, P6 and P8) had three or more organisational levels, namely a CEO, a manufacturing manager and a manufacturing foreman.

\subsection{Production planning and control}

Literature of production planning and control suggests that planning input and MPS should be based on the choice of process (see, e.g., Safizadeh and Ritzman, 1997; Olhager et al., 2001; Olhager and Rudberg, 2002; Miltenburg, 2005; Choudhari et al., 2012a; 2012b). Choudhari et al. (21012a; 2012b) showed that there was consistency in the use of a customer order as planning input and the use of an MTO as the MPS, independently of company size. The results of the present study indicate that the case subcontractors are consistent in their use of customer orders as planning input and in the use of an MTO, or sometimes an engineer-to-order (ETO), as the MPS, consistent with the findings of Choudhari et al. (2012a; 2012b).

Consistent with previous studies (Olhager and Rudberg, 2002; Choudhari et al., 2012a; 2012b), the subcontractors in this study pushed the products through manufacturing and had a centralised planning process. However, no consensus considering a maintenance strategy was found in the study.

Safizadeh and Rizman (1997) argued that the inventory of raw material would be high in a job shop and/or batch flow design, and this was also verified by Choudhari et al. (2012a; 2012b). In the present study, the level of raw material inventory depended on industry. The raw material inventories in the studied foundries were low owing to the manufacturing process, while in the automotive parts and polymer companies, these 
inventories were high. For example, the delivery time for raw material for company P1 was several months, depending on the present availability of that specific material. Companies AP1 and AP2 had larger finished inventories because of large batch sizes and long manufacturing lead times. Determining the level of WIP was complex, since none of the companies in the study measured WIP, but the companies did stress that their level of WIP was high.

\subsection{Sourcing}

The analysis showed no consensus regarding how suppliers were chosen or the relationship with suppliers. Foundries F1, F4, F5, F6, F7, F8 and F9 and automotive parts companies AP1 and AP2 stressed that they had longer-term relationships with suppliers. However, as a representative from foundry F6 said, "we must work more professionally today and rely on delivery times when choosing suppliers rather than on existing acquaintances. Before, we have been too nice to our suppliers." Of the polymer companies, P4, P5, P6 and P7 had long-term relationships with suppliers, while for P1, P2, P3 and P8, the customer decided the suppliers.

Furthermore, the size of the company seemed to influence who was responsible for obtaining products. In the medium-sized companies F2, F4, F8, F9, AP2, P4 and P8, the sales department decided if and how to obtain products. Among the smaller companies in this study, there was no consensus regarding whether the sales department or the CEO was responsible for obtaining products. In the companies where the CEO decided if and how to obtain products, the CEO was also often responsible for sales, i.e. there existed no specific sales function. This can be explained by the smaller organisational size and narrower range of jobs.

\subsection{Process technology}

As discussed in Section 3, the subcontractors in this study had either job shop or batch flow layouts. As can be seen in Table 4, the automotive parts and polymer companies had job shop layouts, while the layout differed in the foundries. According to Choudhari et al. (2012a; 2012b), general-purpose machines are appropriate to either a job shop or a batch flow layout. The foundries had more specialised machines, because of their specific manufacturing processes, and this was also seen in their choice of layouts. The polymer and automotive parts companies had general-purpose machines that were capable of doing different operations and making different products.

According to Choudhari et al. (2012a; 2012b), it is difficult to automate the handling of materials in job shop and batch flow layouts, because of the wide variety of components and the low volumes. All of the subcontractors in this study stressed that they had a lowor medium-sized level of automation. In addition, they agreed that they all wanted a higher level of automation. Because of the manufacturing process, the subcontractors stressed that their layout was static. All of the subcontractors outsourced technology development. The analysis did not reveal any consensus regarding investment in machines, since some of the subcontractors reinvested in machines, while others purchased new machines in order to increase productivity.

The studies by Choudhari et al. (2012a; 2012b) showed similar results with regard to process technology, namely that many of the manufacturing choices were dependent on the process choice. The findings of the present study correspond well to those by Choudhari et al. (2012a; 2012b), since subcontractors mostly made similar manufacturing choices in this category. 
Companies F1 and F3 were ISO-certified. The foundry without ISO certification stressed that their customers did not require the foundry to be ISO-certified. The other companies in the study were ISO-certified.

\subsection{Facilities}

All the subcontractors in the study had small facilities that were located in the countryside or in small towns. Whether a facility was general-purpose or specialised seems to depend on the particular industry. The foundries (F1, F2, F3, F4, F5, F6, F7, F8, F9) had specialised facilities, while the polymer (P1, P2, P3, P4, P5, P6, P7, P8) and automotive parts (AP1, AP2) companies had general-purpose facilities. The foundries were built as such, while, for example, polymer company $\mathrm{P} 4$ had moved to facilities that formerly manufactured non-polymer goods.

Choudhari et al. (2012a; 2012b) indicated that capacity strategy seemed to be related to company size. Olhager et al. (2001) suggested that job shops should have lead capacity. In the current study, only companies F1, F5 and P4 had lead strategy, and there was no congruence of layout or number of employees in these companies. Thus, this study does not confirm the results of previous studies (Choudhari et al., 2012a; 2012b).

\section{Matching the findings with the propositions}

This study is based on four propositions derived from the new institutionalism and SME literature. The first proposition posits that SMEs within the same industry make similar manufacturing choices. The findings of this study do not support this proposition; i.e., subcontractor SMEs in the same industry do not seem to mimic each other's manufacturing choices. It was found that some manufacturing choices in the decision categories of process technology and facilities seem to depend on the particular industry. One example of manufacturing choice that does seem to depend on industry concerns whether machines are of general nature or specialised. However, this might be explained by the fact that companies in the same industry have similar manufacturing processes. Therefore, Proposition 1 has some support on the basis of single manufacturing choices in the decision categories of process technology and facilities.

The second proposition focuses on whether the presence of similar employee groups in SMEs leads to homogenous manufacturing choices. The findings of the study show that there are similarities in the manufacturing choices in the decision category of human resources. It appears that manufacturing choices are influenced by the CEO and the manufacturing manager rather than by the blue collar workers. The companies in the study had a rather flat organisational structure, with only a few white collar workers. This might explain the similar choices in the human resources category. Thus, the second theoretical proposition is confirmed in the human resources decision category.

The third proposition addresses the number of employees. O’Regan and Ghobadian (2004) concluded that size had an influence, but was not the discriminating factor in deciding strategy. It was found in the present study that size influenced some manufacturing choices in all infrastructural decision categories - for example who is responsible for obtaining products. This could also be explained by the number of hierarchical levels in the organisation. Therefore, Proposition 3 has some support in the context of single manufacturing choices.

The fourth proposition focuses on ownership type, and is not supported by the findings of this study. No influence between ownership and manufacturing choice was identified. Therefore, this research support the statements of Säfsten and Winroth (2011) and Yusof 
and Aspinwall (2000) that independent and dependent SMEs could be treated in the same way when considering manufacturing choices.

To summarise the findings and propositions, this study did not find any evidence that subcontractor SMEs mimic each other's overall decision categories and manufacturing choices. Thus, when investigating each decision category separately, propositions including the number of employees and similar employee groups have some support in the infrastructural decision categories.

\subsection{Other factors influencing manufacturing choices in SMEs}

As proposed by Ketokivi and Schroeder (2004), different theories have merit in explaining similarities in manufacturing choices. The empirical findings showed both similarities and differences when considering manufacturing choices. Given these findings, what factors other than those studied can explain the similarities of manufacturing choices in subcontractor SMEs? These factors are derived from both the decision-category literature and the SME literature and were identified during the data analysis. It is proposed that these factors might explain the homogeneity in some of the manufacturing choices.

Management practices. Management practices consist of both a manager's personality and centralised decision making. As pointed out in Section 4.2, numerous studies (e.g., Hudson et al., 2001; Rantakyrö, 2004; Bridge et al., 2009) have shown that SMEs have centralised decision making and are influenced by the manager's personality. Similarities in manufacturing choices among the subcontractors could be related to the centralised decision making and the manager's personality, especially with regard to infrastructural decisions. With decision making being centralised among a few individuals, their personalities and motivations influence their decisions, whether these be strategic or operational. These might be key factors influencing manufacturing choices in subcontractor SMEs.

Competitive environment. Subcontractors relied on customers' requirements, especially for decisions regarding sourcing. For example, some of the polymer companies were dependent on their customers' choices for the suppliers of raw material. This also influenced their relationship with these suppliers. Another example concerns the similar manufacturing choices made by the subcontractors when the customer required them to be ISO-certified. This corresponds to the coercive isomorphism mechanism in new institutional theory, which was described in Section 2.3.1.

Process choice and manufacturing process. Previous studies (e.g., Safizadeh and Ritzman, 1997; Olhager and Rudberg, 2002; Hill and Hill, 2009; Choudhari et al., 2012a; 2012b) have studied decision categories and manufacturing choices from a process choice perspective. Process choice, in particular the choice of manufacturing process, was found to be a relevant factor that could not be neglected in this study, since it influenced various decision categories, including process technology and production planning and control. For example, the age of the machinery and the layout were closely related to the manufacturing process in all cases. Subcontractors with similar manufacturing processes are to some extent forced to make similar decisions considering process technology, since these are dependent on the manufacturing process. Theories of production planning and control suggest that the planning input and MPS are due to process choice (see e.g. Safizadeh and Ritzman, 1997; Olhager et al., 2001; Olhager and Rudberg, 2002; Miltenburg, 2005; Choudhari et al., 2012a; 2012b), which is consistent with the findings of the present study. All the subcontractors had similar planning input, MPS and push systems, similar to what has been seen in other studies of job shop and batch flow layouts (Safizadeh and Ritzman, 1997; Miltenburg, 2005; Choudhari et al., 2012a; 2012b). Considering this, process choice is a factor that makes subcontractor SMEs mimic each 
other in their manufacturing choices for production planning and control and process technology.

\section{Discussion}

This paper has investigated whether subcontractor SMEs make homogenous manufacturing choices and mimic each other. Four propositions that include factors that might influence manufacturing choices in SMEs were developed. The empirical results indicate that subcontractor SMEs do not mimic each other's manufacturing choices on the decision category level. However, subcontractors sometimes make similar manufacturing choices in the decision categories. This could be explained by Propositions 1, 2 and 3, for the industry, the employee groups and the size of the company. Therefore, the propositions have been confirmed in the context of single manufacturing choices. However, Proposition 4, for ownership, has been refuted.

This study has focused on two of the three mechanisms in new institutionalism theory: mimetic and normative forces (DiMaggio and Powell, 1983; St. John et al., 2001). Some support for these two mechanisms has been found in individual manufacturing choices. In particular, the normative mechanism that is associated with similarities among employee groups has been supported in a few manufacturing choices. Moreover, it has also been observed that competitive environments might influence similarities in manufacturing choices. This is associated with coercive isomorphism. Therefore, new institutionalism seems to be useful in explaining institutional influences when making manufacturing choices in SMEs. Thus, the empirical findings reveal that other factors also influence manufacturing choices, such as SME characteristics and process choices. Therefore, the findings of this study are in partial agreement with new institutionalism, which proposes that homogeneity results from institutional pressures. As the phenomenon of context is complex, it can be assumed that new institutionalism explains one part, with SME characteristics and process choice explaining the remaining parts when the whole context is viewed.

Surprisingly, ownership does not seem to influence any of the manufacturing choices (Proposition 4). Ownership is often mentioned as one of the key characteristics of SMEs, since the owner influences most of the decisions as a result of centralisation and informality (Bridge et al., 2009). Ghobadian and O'Regan (2006) investigated ownership in both dependent and independent SMEs and found differences between the two structures with regard to strategic planning and strategy implementation. One possible explanation for this is that ownership influences strategic activities and strategic decisions, but is not as influential on decisions at an operational level. Another explanation might be that factors other than ownership are more significant for making manufacturing choices.

Various studies have emphasised the influence of process choice on decision categories (e.g., Safizadeh and Ritzman, 1997; Olhager and Rudberg, 2002; Hill and Hill, 2009; Choudhari et al., 2012a; 2012b). According to Ketokivi and Schroeder (2004), the effects of institutional arguments should be eliminated before investigating internal relationships. This study aimed at first investigating new institutional arguments, followed by some of the most common characteristics of SMEs, such as size and ownership. Since process choice is included in the internal relationships, it was not included in the theoretical propositions. However, the empirical findings as well as the results of previous studies show the relevance of including process choice as a contingency factor.

The results of the study described in this paper contribute to make appropriate manufacturing choices to support competitive priorities and the manufacturing strategy. Decision makers must be aware that making a manufacturing choice may influence other manufacturing choices as well as competitive priorities. The empirical evidence from this 
study suggests that subcontractor SMEs are not aware of why they make certain choices in manufacturing. This may lead to a situation where manufacturing choices do not match manufacturing strategy, a phenomenon first identified by Skinner (1969), or where manufacturing choices influence other manufacturing choices or competitive priorities negatively. Therefore, it is important for manufacturing managers to understand why they make certain manufacturing choices and how these choices influence their manufacturing strategies and competitive priorities.

\section{Conclusion}

The aim of this paper was to investigate whether subcontractor SMEs mimic each other's manufacturing choices. This research also sought to further understand the decision categories and manufacturing choices in subcontractor SMEs, a topic that is rarely discussed. The analysis considered four theoretical propositions, which were based on either new institutionalism theory or SME theory. A multiple case study with 19 subcontractor SMEs in Sweden was conducted, and the manufacturing choices and patterns were identified and related to the four propositions. The findings showed that variations exist in manufacturing choices in the respondent subcontractor SMEs. Overall, subcontractor SMEs seemed not to mimic each other's decision categories, although individual manufacturing choices in a particular decision category could be similar. Therefore, the propositions had little support on an overall level. For individual manufacturing choices, there were similarities depending on the number of employees (small or medium-sized), and the employee groups were identified. No relationship was found between manufacturing choices and ownership.

As proposed by Ketokivi and Schroeder (2004), different theories have merits in explaining similarities in manufacturing choices. Some of these similarities were not explained by any of the propositions, and therefore other factors were investigated. Factors that might influence the homogeneity of manufacturing choices were found to be process choice, management practices, markets and customers. We conclude that new institutionalism theory can be useful as one explanation of similarities in manufacturing choices in subcontractor SMEs, but other factors must also be considered.

This study confirms the results of previous research showing that SMEs are not a homogenous group (Barad and Gien, 2001; Cagliano and Spina, 2002; O’Regan and Ghobadian, 2004; Assarlind and Gremyr, 2013), in contrast to those studies that have treated SMEs as generic units independent of industry and of whether they are original equipment manufacturers or a subcontractors (see, e.g., Tsai, 2010; Choudhari et al., 2012a; 2012b). In addition, these results have highlighted the need for further studies of companies in specific industries. Therefore, one contribution of this study is that the nature of a particular industry is not a significant factor when making manufacturing choices. The characteristics that SMEs share have been shown to be of greater importance, since the companies in this study made similar manufacturing choices that could not be explained by the theoretical propositions. Considering this, it is appropriate to study SMEs separately and to investigate further which SME characteristics have the most influence on manufacturing choices. This study has revealed the need to classify and structure SMEs further when doing research in this area.

\section{Limitations and further research}

This study has certain limitations that must be mentioned. The study reinforces the need for more research that is focused on manufacturing decisions and choices in SMEs. All cases were of Swedish SMEs belonging to three different industries, potentially limiting the generalizability of findings to other industries or countries. 
The potential influence of subcontractors or small manufacturers on manufacturing choices has rarely been discussed, with the work of Cagliano and Spina (2002) being an exception, and it should be considered as a potential factor. This implies that the location of a company in the supply chain should be analysed as another possible factor.

Since this has been a first attempt at understanding manufacturing choices in subcontractor SMEs and at understanding why some SMEs mimic each other's manufacturing choices (or not), further studies should be conducted in order to better understand the whole phenomenon of manufacturing choices in SMEs. There are obviously many factors other than those proposed here that can lead to similar manufacturing choices in subcontractor SMEs, and these should be further investigated. Some of these factors can be found in new institutionalism theory, but have not been investigated in this study. Examples are the regulatory and political pressures derived from the macro-environment (coercive isomorphism). Moreover, the pressure of normative isomorphism should be investigated further, since it can be related to organisational culture, history and traditions, as well as to management.

This study has not attempted to find a strategic fit between company performance and manufacturing choices, but it would be of interest to investigate whether such a fit exists.

\section{References}

Alves Filho, A. G., Nogueira, E., and Bento, P. E. G. (2015), “Operations strategies of engine assembly plants in the Brazilian automotive industry”, International Journal of Operations \& Production Management, Vol. 35, No. 3, pp. 817-838.

Alstrup, L. (2000), “Coaching continuous improvement in small enterprises”, Integrated Manufacturing Systems, Vol. 11, No. 3, pp. 165-70.

Assarlind, M. and Gremyr, I. (2013), "Critical factors for quality management initiatives in small-and medium-sized enterprises”, Total Quality Management \& Business Excellence, Vol. 25, No. 4, pp. 397-411.

Barad, M., and Gien, D. (2001), "Linking improvement models to manufacturing strategies - a methodology for SMEs and other enterprises”, International Journal of Production Research, Vol. 39, No. 12, pp. 2675-2695.

Barnes, D. (2002), "The complexities of the manufacturing strategy formation process in practice”, International Journal of Operations \& Production Management, Vol. 22 No. 10, pp. 1090-1111.

Bridge, S., O'Neill, K. and Cromie, S. (2009), Understanding Enterprise, Entrepreneurship and Small Business, 3rd ed., Palgrave Macmillan, Basingstoke, UK.

Cagliano, R., Blackmon, K. and Voss, C. (2001), “Small firms under MICROSCOPE: international differences in production/operations management practices and performance”, Integrated Manufacturing Systems, Vol. 12, No. 7, pp. 469-482.

Cagliano, R. and Spina, G. (2002), “A comparison of practice-performance models between small manufacturers and subcontractors”, International Journal of Operations \& Production Management, Vol. 22, No. 12, pp. 1367-1388.

Carter, S. and Jones-Evans, D. (2006), Enterprise and Small Business: Principles, Practice and Policy, 2nd ed., Financial Times/Prentice Hall, Harlow.

Child, J. (1972), “Organizational Structure, Environment and Performance: The Role of Strategic Choice”, Sociology, Vol. 6, No. 1, pp. 1-22.

Choudhari, S.C., Adil, G.K. and Ananthakumar, U. (2010), “Congruence of manufacturing decision areas in a production system: a research framework", International Journal of Production Research, Vol. 48, No. 20, pp. 5963-5989. 
Choudhari, S.C., Adil, G.K. and Ananthakumar, U. (2012a), "Choices in manufacturing strategy decision areas in batch production system - six case studies”, International Journal of Production Research, Vol. 50, No. 14, pp. 3698-3717.

Choudhari, S.C., Adil, G.K. and Ananthakumar, U. (2012b), "Exploratory case studies on manufacturing decision areas in the job production system”, International Journal of Operations \& Production Management, Vol. 32, No. 11, pp. 1337-1361.

Dangayach, G.S. and Deshmukh, S.G. (2001), "Manufacturing strategy - literature review and some issues”, International Journal of Operations \& Production Management, Vol. 21 No. 7, pp. 884-932.

Dìaz Garrido, E., Martìn-Peña, M.L. and Garcìa-Muiña, F. (2007), “Structural and infrastructural practices as elements of content operations strategy. The effect on a firm's competitiveness”, International Journal of Production Research, Vol. 45, No. 9, pp.2119-2140.

DiMaggio, P. and Powell, W.W. (1983), “The iron cage revisited: Institutional isomorphism and collective rationality in organizational fields", American Sociological Review, Vol. 48, No. 2, pp. 147-160.

Eisenhardt, K. M. (1989), "Building Theories from Case Study Research”, Academy of Management Review, Vol. 14, No. 4, pp. 532-550.

European Commission (2014), “Guide to EU definition of SMEs”, EN NB-60-04-773EN-C 92-894-7909-4, available at:

http://ec.europa.eu/enterprise/policies/sme/facts-figures-analysis/smedefinition/index_en.htm (accessed 28 January 2014).

Garengo, P., Biazzo, S. and Bititci, U.S. (2005), "Performance measurement systems in SMEs: a review for a research agenda", International Journal of Management Reviews, Vol. 7, No. 1, pp. 25-47.

Ghobadian, A. and Gallear, D. (1997), “TQM and organization size”, International Journal of Operations \& Production Management, Vol. 17, No. 2, pp. 121-163.

Ghobadian, A. and O’Regan, N. (2006), “The Impact of Ownership on Small Firm Behaviour and Performance”, International Small Business Journal, Vol. 24, No. 6, pp. 555-586.

Grando, A. and Belvedere, V. (2006), "District's manufacturing performances: A comparison among large, small-to-medium-sized and district enterprises", International Journal of Production Economics, Vol. 104, No. 1, pp. 85-99.

Größler, A. and Grübner, A. (2006), “An empirical model of the relationships between manufacturing capabilities”, International Journal of Operations \& Production Management, Vol. 26, No. 5, pp. 458-485.

Hayes, R.H. and Wheelwright, S.C. (1984), Restoring Our Competitive Edge: Competing Through Manufacturing, John Wiley \& Sons, New York, NY.

Hayes, R. , Pisano, G. , Upton, D. and Wheelwright, S.C. (2005), Operations, Strategy, and Technology - Pursuing the Competitive Edge , John Wiley \& Sons Inc., New York, NY.

Hill, A. and Hill, T. (2009), Manufacturing operations strategy, 3rd ed., Palgrave Macmillan, Basingstoke, UK.

Hilmola, O-P., Lorentz, H., Hilletofth, P., Malmsten, J. (2015), “Manufacturing strategy in SMEs and its performance implications", Industrial Management \& Data Systems, Vol. 115, No. 6, pp.1004-1021.

Hudson, M., Smart, A. and Bourne, M. (2001), “Theory and practice in SME performance measurement systems”, International Journal of Operations \& Production Management, Vol. 21, No. 8, pp. 1096-1115. 
Hudson Smith, M. and Smith, D. (2007), "Implementing strategically aligned performance measurement in small firms", International Journal of Production Economics, Vol. 106, No. 2, pp. 393-408.

Jagoda, K., and Kiridena, S. (2015), “Operations strategy processes and performance: Insights from the contract apparel manufacturing industry”, Journal of Manufacturing Technology Management, Vol. 26, No. 2, pp. 261-279.

Julien, P-A. (1998), The State of the Art in Small Business and Entrepreneurship, Ashgate, Aldershot, UK.

Ketokivi, M.A. and Schroeder, R.G. (2004), "Strategic, structural contingency and institutional explanations in the adoption of innovative manufacturing practices", Journal of Operations Management, Vol. 22, No. 1, pp. 63-89.

Koc, T. and Bozdag, E. (2007), “An empirical research for CNC technology implementation in manufacturing SMEs”, The International Journal of Advanced Manufacturing Technology, Vol. 34, No. 11-12, pp. 1144-1152.

Leong, G.K., Snyder, D.L. and Ward, P.T. (1990), "Research in the process and content of manufacturing strategy”, Omega, Vol. 18, No. 2, pp.109-122.

McCartan-Quinn, D. and Carson, D. (2003), "Issues which Impact upon Marketing in the Small Firm”, Small Business Economics, Vol. 21, No. 2, pp. 201-213.

Miller, J.G. and Roth, A.V. (1994), “A Taxonomy of Manufacturing Strategies”, Management Science, Vol. 40, No. 3, pp. 285-304.

Mills, J. , Platts, K. and Gregory, M. (1995), “A framework for the design of manufacturing strategy processes - a contingency approach”, International Journal of Operations \& Production Management, Vol. 15 No. 4, pp. 17-49.

Miltenburg, J. (2005), Manufacturing Strategy: How to Formulate and Implement a Winning Plan, 2nd ed., Productivity Press, New York, NY.

Narasimhan, R. and Das, A. (1999), “An empirical investigation of the contribution of strategic sourcing to manufacturing flexibilities and performance”, Decision Science, Vol. 30, No. 3, pp. 683-718.

Nguyen, T.V. and Bryant, S.E. (2004), "A Study of the Formality of Human Resource Management Practices in Small and Medium-size Enterprises in Vietnam”, International Small Business Journal, Vol. 22, No. 6, pp. 595-618.

Olhager, J. and Rudberg, M. (2002), “Linking manufacturing strategy decisions on process choice with manufacturing planning and control systems", International Journal of Production Research, Vol. 40, No. 10, pp. 2335-2351.

Olhager, J., Rudberg, M. and Wikner, J. (2001), “Long-term capacity management: linking the perspectives from manufacturing strategy and sales and operations planning”, International Journal of Production Economics, Vol. 69, No.2, pp.21525.

O’Regan, N. and Ghobadian, A. (2004), “Testing the homogeneity of SMEs: The impact of size on management and organisational processes”, European Business Review, Vol. 16, No. 1, pp. 64-79.

Paiva, E. L., Roth, A. V. and Fensterseifer, J. E. (2008), “Organizational knowledge and the manufacturing strategy process: A resource-based view analysis”, Journal of Operations Management, Vol. 26, No. 1, pp. 115-132.

Radnor, Z. J., and Boaden, R. (2004), “Developing an understanding of corporate anorexia”, International Journal of Operations \& Production Management, Vol. 24, No. 4, pp. 424-440.

Rantakyrö, L. (2004), Still searching the best way...: a multiple-case study in small industrial organizations, Ph.D. dissertation, Luleå University of Technology, Luleå, Sweden. 
Raymond, L. (2005), “Operations management and advanced manufacturing technologies in SMEs: A contingency approach”, Journal of Manufacturing Technology Management, Vol. 16, No. 8, pp. 936-955.

Safizadeh, M.H. and Ritzman, L.P. (1997), "Linking performance drivers in production planning and inventory control to process choice”, Journal of Operations Management, Vol. 15, No. 4, pp. 389-403.

St. John, C.H., Cannon, A.R. and Pouder, R.W. (2001), "Change drivers in the new millennium: implications for manufacturing strategy research”, Journal of Operations Management, Vol. 19, No. 2, pp. 143-160.

Sear, L., Scurry, T., Swail, J. and Down, S. (2012), “Graduate recruitment to SMEs: final report”, available at http://dera.ioe.ac.uk/16398/1/bis-13-546-graduate-recruitmentto-smes.pdf (accessed 6 March 2014).

Skinner, W. (1969), "Manufacturing - Missing Link in Corporate Strategy”, Harvard Business Review, May-June, pp. 136-145.

Slack, N. and Lewis, M. (2011), Operations Strategy, 3rd ed., Prentice Hall, Harlow, UK.

Sousa, R. and Voss, C.A. (2008), “Contingency research in operations management practices”, Journal of Operations Management, Vol. 26, No. 6, pp. 697-713.

Spring, M. and Dalrymple, J.F. (2000), "Product customization and manufacturing strategy”, International Journal of Operations \& Production Management, Vol. 20, No. 4, pp. 441-467.

Stewart, J. and Knowles, V. (2000), "Graduate recruitment and selection practices in small businesses”, Career Development International, Vol. 5, No. 1, pp. 21-38.

Storey, D.J. (1994), Understanding the Small Business Sector, Routledge, London, UK.

Swamidass, P.M. and Kotha, S. (1998), "Explaining manufacturing technology use, firm size and performance using a multidimensional view of technology", Journal of Operations Management, Vol. 17, No. 1, pp. 23-37.

Säfsten, K. and Winroth, M. (2011), "Manufacturing strategies supporting competitiveness in SMMEs", Proceedings 18th International Annual EurOMA conference, 3- 6 July 2011, Cambridge, UK.

Säfsten, K., Winroth, M. and Stahre, J. (2007), “The content and process of automation strategies”, International Journal of Production Economics, Vol. 110, No. 1-2, pp. 25-38.

Thakkar, J., Kanda, A. and Deshmukh, S.G. (2012), "Supply chain issues in Indian manufacturing SMEs: insights from six case studies”, Journal of Manufacturing Technology Management, Vol. 23, No. 5, pp. 634-664.

Tsai, C.J. (2010), "HRM in SMEs: homogeneity or heterogeneity? A study of Taiwanese high-tech firms", The International Journal of Human Resource Management, Vol. 21, No. 10, pp. 1689-1711.

Voss, C. A. (1995), “Alternative paradigms for manufacturing strategy”, International Journal of Operations \& Production Management, Vol. 15, No. 4, pp. 5-16.

Ward, P.T. and Duray, R. (2000), "Manufacturing strategy in context: environment, competitive strategy and manufacturing strategy", Journal of Operations Management, Vol. 18, No. 2, pp. 123-138.

Woodward, J. (1958), Management and Technology, Her Majesty's Stationery Office, London, UK.

Yin, R.K. (2009), Case Study Research: Design and Methods, 4th ed., Sage Publications, Thousand Oaks, CA. 
Yusof, S.M. and Aspinwall, E. (2000), “Total quality management implementation frameworks: comparison and review”, Total Quality Management, Vol. 11, No. 3, pp. 281-294. 